\section{O resgate das Ciências Humanas no Âmbito das Ciências da Comunicação}

\section{Guilherme Moreira FERNANDES ${ }^{1}$}

MARQUES DE MELO, José; FERNANDES, Guilherme Moreira. Pensamento Comunicacional Brasileiro: o legado das Ciências Humanas. Vol. 1: História e Sociedade. São Paulo: Paulus, 2014.

Quem conhece o professor José Marques de Melo sabe de sua preocupação com o resgate da memória em torno do que foi produzido no âmbito das Ciências da Comunicação. Desde seu primeiro livro "Comunicação Social: teoria e pesquisa" (Vozes, 1970) já podemos perceber sua preocupação em traçar amplas referências bibliográficas que podem ser utilizadas para aprofundar determinado assunto. Outra característica do professor, assumida já na década de 1960, é o compartilhamento de sua experiência com alunos. Neste livro de estreia, o professor apresenta resultados de pesquisas que foram desenvolvidos por alunos no âmbito do curso de Jornalismo da Cásper Líbero. E, nota-se, são temas ousados para a época. Como a importância da História em Quadrinhos e a recepção da telenovela. Os anos se passaram e essas características permaneceram. Não é difícil de encontrar obras do professor com grandes indicações bibliográficas e, uma análise mais atenta, revela que autores não oriundos do campo comunicacional também fazem parte desta lista.

Nesta segunda década do século XXI podemos observar diversos projetos do professor que visam resgatar essa memória, chamo atenção especial ao Pensacom. Pesquisadores todos os estados da federação foram motivados a produzir o legado comunicacional de cada um das regiões. O estado do Piaú foi o pioneiro, sendo seguido pelos estados de Alagoas, Minas Gerais e Goiás. Em São Paulo, foi produzido um amplo debate, que resultou na publicação de três (grandes) livros, publicados no início de 2015 e organizado por sua discípula Maria

1 Doutorando em Comunicação e Cultura pela Universidade Federal do Rio de Janeiro. E-mail: gui_facom@hotmail.com.
Cristina Gobbi. A Universidade de São Paulo, instituição em que se consolidou como o principal pesquisador da área e instituição que lhe deu o título de primeiro doutor em Jornalismo do Brasil, não foi esquecida. Cinco volumes (três publicados em 2010 e dois em 2015) relembram textos marcantes produzidos em diversos momentos. A Folkcomunicação, primeira e única teoria da Comunicação genuinamente brasileira, também não foi esquecida. Tive a honra de editar a obra "Metamorfose da Folkcomunicação" (Editae Cultural, 2013), reunindo textos de todas as épocas em suas 1100 páginas. Agora, é a vez do legado das Ciências Humanas. Projeto realizado em parceira com a Paulus e que será dividida em três volumes. O primeiro, história e sociedade, foi lançado em setembro de 2014. Os dois seguintes chegarão aos leitores no decorrer de 2015.

O livro está em consonância com as preocupações do professor Marques de Melo de resgatar e trazer à baila o estado da arte da Comunicação. Ao contrário de outras publicações com vistas aos teóricos e pensadores da comunicação stricto sensu este livro traz uma abertura e uma visão do processo comunicacional de forma lato. Todos os trinta e cinco autores reunidos nos "texto-base" não são oriundos do campo comunicacional, são reconhecido por pares em outras esferas da grande área das Ciências Humanas e Sociais. Contudo, suas diversas contribuições ao universo comunicacional os fazem autores referências. O caráter que diferencia esta de tantas outras antologias é a presença dos intérpretes-leitores. Estes sim pesquisadores atuantes no campo comunicacional que direcionaram seu olhar para a comunicação inscrita e circunscrita nestes trintas e seis textos.

Também consonante com a perspectiva pedagógica do professor Marques de Melo, o livro apresenta visões das mais distintas gerações de pesquisadores. De mestrandos a renomados e prestigiados pesquisadores do campo comunicacional. As diversas orientações metodológicas e epistemológicas coexistem lado a lado. O resultado é um amplo mosaico da sociedade e cultura brasileira à luz das Ciências da Comunicação.

Optamos por seguir uma estratégia similar a que fizemos no "Metamorfose da Folkcomunicação", ou seja, a cada "texto-base" seria acrescentado um "texto introdutório" e haveria um outro texto amarrando cada uma das sessões. Após diversas discussões, modificamos o formato e a cada "texto-base" foram acrescentados dois outros textos. O primeiro de natureza biobibliográfica, ressaltando a trajetória do autor e a importância do texto, e outro de natureza metodológica, trazendo novas contribuições ao texto. Dividimos a produção em dois 
momentos, assim, os autores das notas metodológicas tiveram acesso aos textos biobibliográficos, evitamos possíveis repetições desnecessárias.

Cada uma das seis seções presentes no conjunto da obra tiveram outros três textos. O primeiro, denominado de "introdução", visa apresentar o conjunto de textos em consonância com o título da seção. O segundo, que chamamos de "contextualização teórica", publicado após os "textos-base" e suas respectivas notas, tem como objetivo amarrar os seis textos presentes da seção, visto que os autores são filiados a distintas áreas e não apresentam diálogos per se. Por fim, "reflexões pedagógicas" é o texto de fecho e traz contribuições para a leitura reflexiva. Os exegetas da "contextualização teórica" tiveram acesso às notas biobibliográficas e os convidados para redigirem as "reflexões pedagógicas", por sua vez, tiveram acesso aos textos de "introdução".

A escolha dos exegetas não foi arbitrária. Procuramos pesquisadores que possuem afinidade com o autor ou o tema refletido no texto. Conseguimos representantes de todos os estados da federação. Do Rio Grande do Sul ao Amapá, da Paraíba ao Acre. Conseguimos representantes de todos os Estados da federação. Do Rio Grande do Sul a Roraima, da Paraíba ao Acre. Mobilizamos 111 pesquisadores, além dos 35 pensadores que compõem os "textos-base", totalizando $146 \mathrm{au}$ tores. Também há representantes internacionais, tanto nos "textos-base" (Lévi-Strauss, Willems, Dreifuss) e na condição de representantes de entidades científicas, caso dos iberos Luís Humberto Marcos (AssIbercom) e Margarida Ledo (Lusocom).

Este volume está dividido em duas seções. A primeira denominada de "Comunicação Humana: Gênese e Evolução” apresenta textos de Lévi-Strauss, Câmara Cascudo, Jarbas Maciel, Florestan Fernandes, Barbosa Lima Sobrinho e Virgilio Noya Pinto. Esta talvez seja a seção quem menos trata da comunicação no sentido imputado pelos comunicólogos. É interessante notar que os três textos de síntese (introdução, contextualização teórica e reflexões pedagógicas) trazem distintos questionamentos e abordam esta questão de forma quase contraditória. Fica então o instigante convite para o leitor pensar a comunicação humana em seus diversos vieses: seja na relação de parentesco (Lévi-Strauss), nas relações de vizinhança (Cascudo), na antropologia da educação (Maciel), no folclore lúdico (Fernandes), nos usos da língua portuguesa (Lima Sobrinho) ou por meio das relações históricas (Noya Pinto). Certamente as notas que abrem e fecham os textos ajudaram o leitor neste processo.
A segunda parte "Comunicação: processo social básico" traz subsídios para a compreensão das diversas formas que o processo comunicativo está presente. Em diálogo temos textos de Willems, Maynard Araújo, Paulo Freire, Diégues Júnior, Antônio Cândido e Fernando de Azevedo. Novamente o debate teórico da comunicação não é a tônica de nenhum dos textos. O que vamos encontrar são situações em que a comunicação está presente. É interessante observar como a comunicação é tratada em diferentes angulações. A síntese de cada debate mostra especificidades das subáreas da comunicação. Nesse ínterim, apresentamos debates sobre a cidade (Willems), as comunidades periféricas (Maynard Araújo), a educomunicação (Paulo Freire), os imigrantes (Diégues Jr.), o folhetim (Cândido) e a opinião pública (Azevedo). Os textos de sínteses, por sua vez, ampliam o debate e a visão da comunicação como processo social.

O segundo volume apresenta as seções "Comunicação: fenômeno cultural” com textos de Egon Schaden, Gilberto Freyre, Rubem Oliven, Alfredo Bosi, Darcy Ribeiro e Vamireh Chacon e "Comunicação: sistema de poder" com os escritos de Carlos Guilherme Mota, José Nilo Tavares, René Dreifuss, Ruth Cardoso, Juan Diaz Bordenave e Celso Furtado. Já o terceiro volume é composto pelas seções "Comunicação: fluxos comportamentos (consumo, participação e opinião público)" com as pesquisas de Gabriel Cohn, Arthur Ramos, Cândido Mendes, Samuel Profomm Neto, Ingrid Sarti e Octavio Ianni e "Comunicação: ciências sociais aplicadas" com estudos de Octavio Eduardo, Florestan Fernandes, Dante Moreira Leite, Maria Isaura Pereira de Queiróz, Luiz da Costa Lima e Fernando Henrique Cardoso.

Neste volume participaram como exegetas os seguintes pesquisadores: Anderson Lopes da Silva (UFPR), André Giulliano Mazini (UFGD), Ângela Cristina Salgueiro Marques (UFMG), Antônio Hohlfeldt (PUC-RS), Bruno Augusto Amador Barreto (Unigran), Christina Ferraz Musse (UFJF), Claiton César Czizewski (UFPR), Edgard Rebouças (UFES), Erotilde Honório Silva (Unifor), Evandro José Medeiros Laia (UFRJ), Felipe Pena (UFF), Francielle Maria Modesto Mendes (UFAC), Francisco Aquinei Timóteo Queirós (UFAC), Júnior Pinheiro (UFPB), Lídia Ramires (UFAL), Marcelo Sabbatini (UFPE), Marcio Fernandes (Unicentro), Marcius Cortez (UFPE), Marcos Paulo da Silva (UFMS), Maria Berenice da Costa Machado (UFRGS), Maria Érica de Oliveira Lima (UFRN), Maria José Oliveira (UFSJ), Maria Madalena Fernandes (CES-JF), Marialva Barbosa (UFRJ), Marli dos Santos (Umesp), Moisés de Lemos Martins (Universidade do Minho/Confibercom), Patri- 
cia Bandeira de Melo (Fundaj), Paulo Roberto Figueira Leal (UFJF), Regiane Regina Ribeiro (UFPR), Roberta Manuela Barros de Andrade (UECE), Rodrigo Gabrioti (ESAMC-Sococaba), Rosa Maria Cardoso Dalla Costa (UFPR), Sandra Pereira Tosta (PUC-MG), Sebastião Guilherme Albano (UFRN), Sérgio Mattos (UFRB), Sônia Jaconi (Umesp), Tyciane Cronemberger Viana Vaz (UFPI), Verônica Dantas Meneses (UFT), Wagner da Costa Silva (UFAC) e Walmir de Albuquerque Barbosa (UFAM).

O livro é recomendado para todos os estudantes e profissionais da Comunicação Social e suas mais diversas áreas - Jornalismo, Radialismo, Relações Públicas, Editoração etc., bem como para estudantes e profissionais das Ciências Humanas - Sociologia, Antropologia, Ciência Política, Economia, Psicologia, Direito, Letras, História, Geografia, etc. Há um pouquinho de cada um desses diversos campos nos textos que fazem parte dessa obra, que já é referência. 